\title{
Do You Believe the Climate Is Changing? Answers From New Survey Research
}

\section{Three Questions About Climate Change}

I n 2010, Carsey Institute researchers began including three new questions about climate change on the Granite State Poll, which surveys New Hampshire residents four times each year. We also started using these questions on the Community and Environment in Rural America (CERA) surveys being conducted in selected rural areas around the United States. ${ }^{1}$ Alongside many other questions concerning people's lives and opinions, the climate questions ask how much people feel they understand about global warming or climate change; whether they personally believe that it is happening now and, if so, why; and whether they think most scientists agree. The questions are neutrally worded, concern beliefs about present facts rather than possible future events, and are designed around the central point made in statements by scientists.

Each telephone interview for these surveys lasted around 10 to 20 minutes. Questions covered opinions on a variety of topics, along with respondent background information. The Granite State Poll traditionally focuses on politics and election issues, such as the state's famous presidential primaries. CERA surveys are not political but ask people about their views concerning family, community, and local environment. Both provide insights on the range of opinions held by people with different backgrounds, situations, and outlooks.

An earlier Carsey brief presented results from the first New Hampshire poll to carry the three climate questions. ${ }^{2}$ Results from later New Hampshire polls and regional CERA surveys were compared in a subsequent issue brief. ${ }^{3}$ In August 2011, we conducted a fifty-state national survey called NCERA that asked about climate along with other CERA questions, creating benchmark data for national-regional comparisons. In this brief we compare the nationwide climate change answers with those from New Hampshire. State and national responses turned out broadly similar, but with some differences in the details.

\section{Key Findings}

- More than half the respondents on both surveys agree that climate change is currently happening, caused mainly by human activities. Substantial minorities, however, believe instead that climate is changing because of natural forces. Only a few believe that climate is not changing.

- Similarly, more than half the respondents on both surveys think most scientists agree that humancaused climate change is happening.

- Most people on both surveys feel that they understand either a great deal or a moderate amount about global warming or climate change.

- Deep partisan divisions affect both personal beliefs about climate change and perceptions of agreement among scientists. Democrats are much more likely to state they believe that climate change is happening, caused mainly by human activities. Republicans are much more likely to say they believe either that climate change is not happening, or that it is, but for natural reasons.

- A large majority of Democrats think that most scientists agree climate is changing due to human activities, but a majority of Republicans think there is little agreement among scientists on this point.

- A series of similar polls in New Hampshire show little change over the past two years. Democrats and Republicans who are most confident in their understanding of climate change stand the farthest apart, both in their personal beliefs about climate change and in their perceptions about scientists.

- This partisan division among respondents who feel they understand the issue suggests that they are getting information from different sources. Nationally, most Democrats, but only a minority of Republicans, say they trust scientists as a source of information about environmental issues. 


\section{How Much Do You Understand?}

Our first climate question asks whether people feel they understand a great deal, a moderate amount, only a little, or nothing at all about global warming or climate change. Figure 1 charts New Hampshire and national results. Most respondents express confidence that they understand either a great deal or a moderate amount. New Hampshire respondents are slightly more confident ( 78 versus 72 percent), and less likely to say they understand little or nothing (23 versus 28 percent).

Figure 1. HOW MUCH DO YOU UNDERSTAND ABOUT GLOBAL WARMING OR CLIMATE CHANGE ISSUES? RESULTS FROM NEW HAMPSHIRE (TOP) AND NATIONAL (BOTTOM) SURVEYS CONDUCTED IN SUMMER 2011.

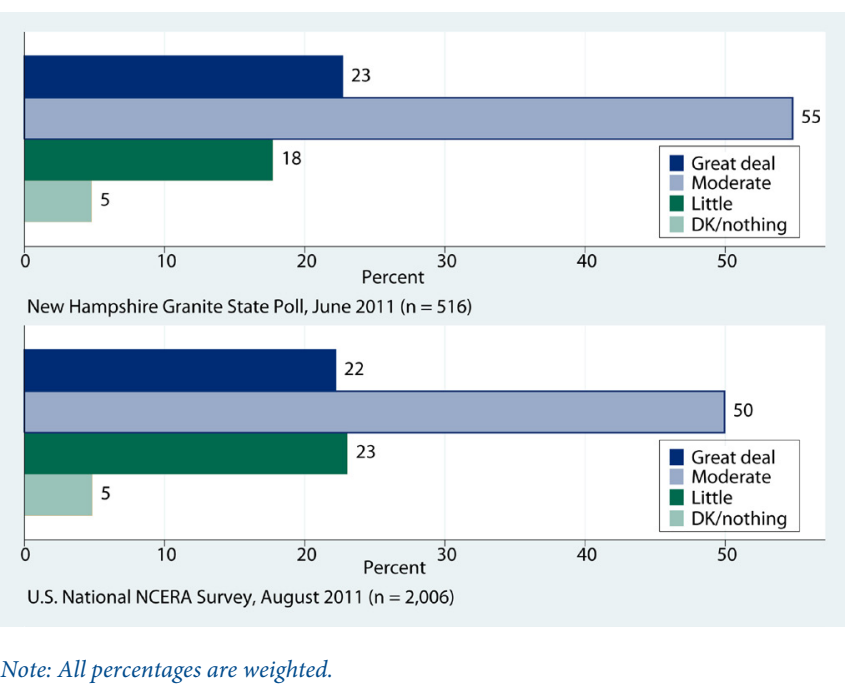

As we see later, more confident respondents tend also to be more polarized, which relates to another difference between New Hampshire and U.S. results. The most striking message from Figure 1, however, is not the small difference between New Hampshire and the United States, but rather the large similarity: most people feel that they understand this challenging topic.

\section{Do You Believe the Climate Is Changing?}

A central point of statements on climate change made by the major scientific organizations has been that climate change is happening now, caused mainly by human activities. Without identifying the source, we included this point as one of three choices in asking people what they believe personally. A majority selected that option: 55 percent of New Hampshire respondents, and 52 percent nationally, believe that climate change is happening now, caused mainly by human activities. However, substantial minorities (35 percent in New Hampshire or 39 percent nationally) believe that climate change is happening but caused mainly by natural forces (Figure 2). Thus, we see about 90 percent agreement that climate change is happening, but substantial disagreement on why.

Figure 2: WhAT DO YOU PERSONALLY BELIEVE ABOUT CLIMATE CHANGE?

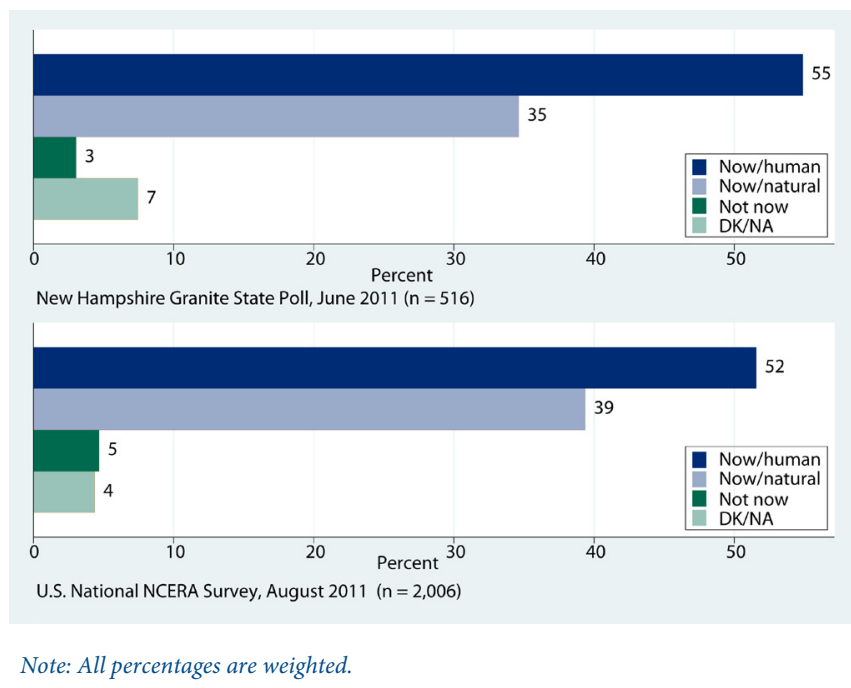

This disagreement falls largely along party lines. The upper plot in Figure 3 divides New Hampshire responses according to whether people consider themselves to be a Democrat, Independent, or Republican. The lower plot shows the same breakdown for the national survey. Deep partisan divisions appear on both. The division is deepest in New Hampshire, where the Democrat-Republican gap is 51 points: 82 percent of Democrats but just 31 percent of Republicans believe climate is changing due to humans. On the national survey the gap is 39 points (70 versus 31 percent).

On both surveys, Independents occupy a middle position between Democrats and Republicans. In the regional CERA studies we see a similar Democrat-Independent-Republican gradient on nearly all environment-related questions, from big issues such as renewable energy to local problems such as beach pollution. ${ }^{4}$ Regarding climate change, Independents split between human and natural causes.

Small minorities on either survey believe that climate is not changing. Although small, these minorities are mostly Republican. Among national respondents, 9 percent of Republicans and 2 percent of Democrats believe that climate change is not happening. The New Hampshire survey finds a similar ratio, 5 percent of Republicans and 1 percent of Democrats. The low levels in New Hampshire, also seen on other surveys, might reflect awareness of the tangible evidence for climate change 


\section{Figure 3: Personal belief by political party.}

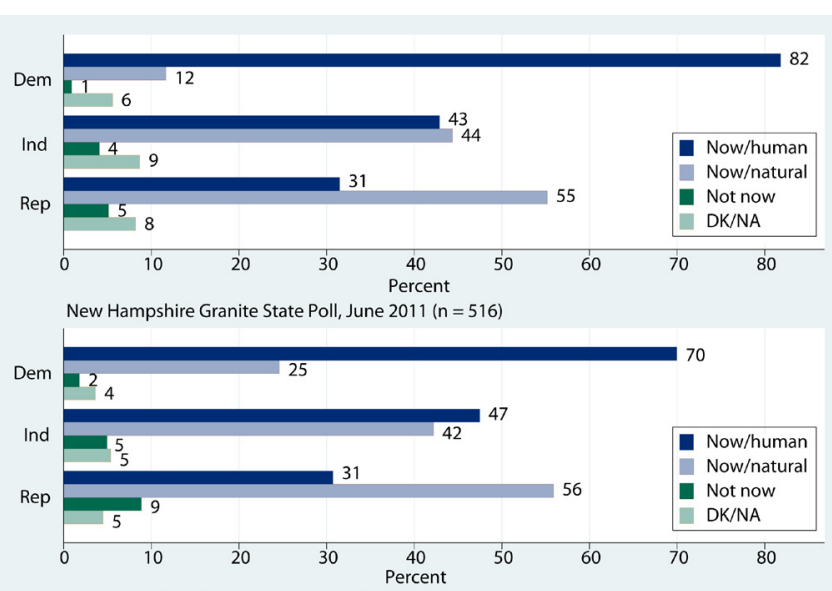

U.S. National NCERA Survey, August $2011(n=2,006)$

Note: All percentages are weighted.

in that state. This evidence includes such things as increasingly frequent mild winters, earlier ice-out dates on the big lakes, and seasonal shifts causing trouble for maple syrup production. ${ }^{5}$

\section{Do You Think That Most Scientists Agree?}

All the major organizations of scientists with relevant expertise in the United States, along with many others abroad, have published statements expressing their views on climate change. For example, the statement by the American Association for the Advancement of Science (110,000 members) reads in part: "The scientific evidence is clear: global climate change caused by human activities is occurring now, and it is a growing threat to society." 6

The American Geophysical Union (50,000 members) states, "Many components of the climate system...are now changing at rates and in patterns that are not natural and are best explained by the increased atmospheric abundances of greenhouse gases and aerosols generated by human activity during the 20th century."

Similar statements have been endorsed by the American Statistical Association, American Meteorological Society, and many others. ${ }^{8}$ They have also been made by national academies of leading scientific nations, ${ }^{9}$ and appear with more detail in international assessments of research results. ${ }^{10}$ Further evidence of the consensus comes from a 2008 survey of more than 3,000 Earth scientists, which found 90 percent agreement that mean global temperatures have generally risen compared with pre-1880s levels, and 82 percent agreement that human activities are a significant contributing factor to temperature change. Among scientists who actively publish research in any field, agreement on the second question approached 90 percent, and over 96 percent among climatologists publishing on climate change. ${ }^{11}$ In May 2010, 255 members of the U.S. National Academy of Sciences wrote in an open letter published in Science, the leading interdisciplinary journal: "The planet is warming due to increased concentrations of heat-trapping gases in our atmosphere.... Most of the increase in the concentration of these gases over the last century is due to human activities, especially the burning of fossil fuels and deforestation." 12

A central point of agreement found in each of these statements is that climate is changing now, caused mainly by human activities. One of our questions focuses on this scientific agreement. We ask respondents which statement they think is more accurate: "Most scientists agree climate change is happening now, caused mainly by human activities," or "There is little agreement among scientists whether climate change is happening now, caused mainly by human activities.” As Figure 4 shows, majorities on both surveys recognize that most scientists agree.

Figure 4: Do you THINK THAT MOST SCIENTISTS AgReE, OR IS THERE LITTLE AGREEMENT AMONG SCIENTISTS?

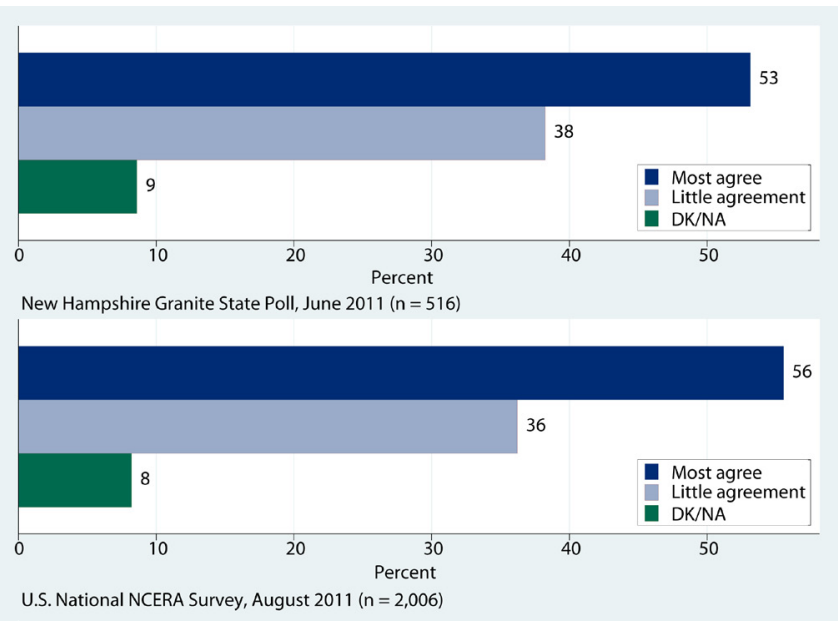

Note: All percentages are weighted.

This picture sharpens, however, when we break it down by party (Figure 5). Although a large majority of Democrats think that most scientists agree, more than half the Republicans instead think that there is little agreement among scientists. Independents once again hold the middle position. Perceptions about scientists thus mirror personal beliefs, and both vary with politics. The Democrat-Republican gap regarding scientific agreement, 51 points (New Hampshire) or 31 points (United States), nearly matches what we saw earlier regarding personal beliefs. 
Figure 5: Do SCIENTISTS AgreE? By POlitical PARTy, ON NEW HAMPSHIRE AND NATIONAL SURVEYS.

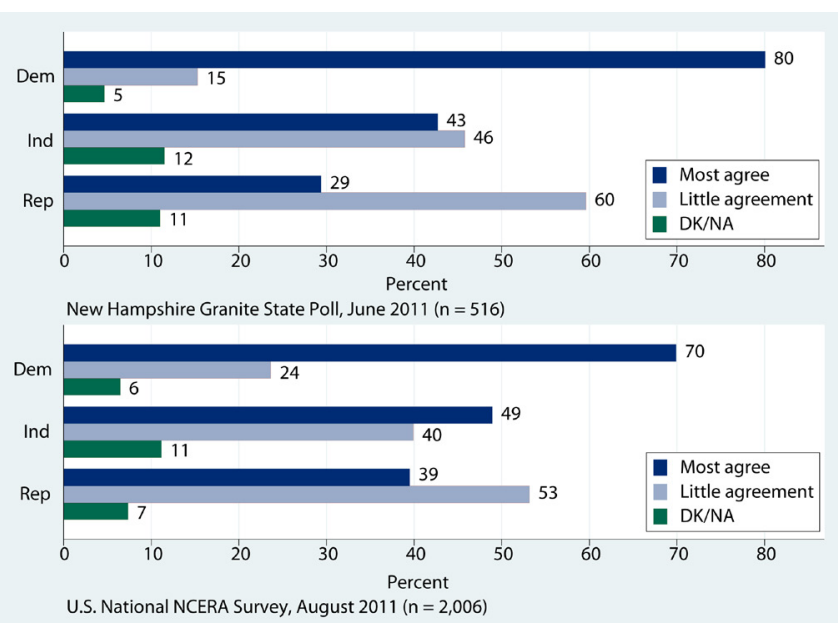

Note: All percentages are weighted.

\section{Partisan Understanding of Science}

Figure 1 shows that most people feel they have either a great deal or moderate amount of understanding about global warming or climate change. This "understanding" has different content, however, depending on political outlook. Democrats who feel they have great or moderate understanding overwhelmingly tend to believe that climate change is happening now, caused mainly by human activities, and that most scientists agree on this point. By equally great margins, however, Republicans with similar confidence in their understanding tend not to believe climate is changing due to humans, or that most scientists agree. In other words, what people mean by "understanding" varies with their political beliefs, which lead them to opposite perceptions about science. This pattern appears in both New Hampshire and national data, as well as many other surveys. ${ }^{13}$

Figure 6 shows consistency in this pattern across seven Granite State Polls. For this graph, representing more than 3,600 interviews, respondents were subdivided into four groups. The top line tracks the percent believing in human-caused climate change among Democrats who say that they have a great or moderate understanding. The bottom line tracks this percentage among Republicans who say they have great or moderate understanding. Two other lines track Democrats and Republicans who say they understand little or nothing. Finally, a thick line through the middle shows the overall percent for all parties combined. This overall percent does not change much over the seven polls. Nor do the lines representing Democrats with great or moderate understanding (around 80 percent) and Republicans with great or moderate understanding (below 30 percent). Their co-partisans with little or no understanding, however, appear less steady and less far apart.
Figure 6: Percent who believe that Climate CHANGE IS HAPPENING NOW, CAUSED MAINLY BY HUMAN ACTIVITIES, BY POLITICAL PARTY AND SELF-ASSESSED UNDERSTANDING. RESUlTS FROM SEVEN NEW HAMPSHIRE POLLS CONDUCTED APRIL 2010 TO OCTOBER 2011.

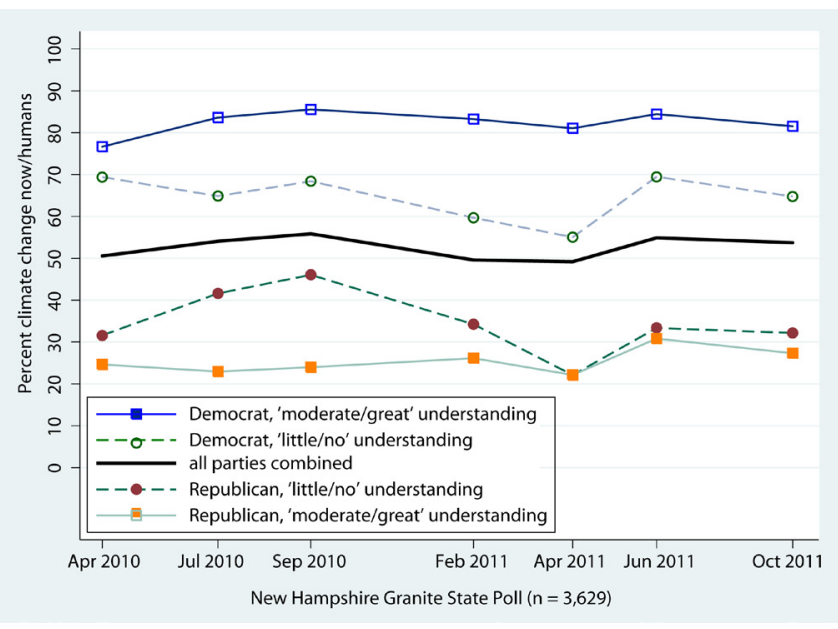

Note: All percentages are weighted.

These patterns suggest that many people derive their information and sense of understanding from sources chosen to align with their politics. Figure 7 gives results from another question on the NCERA survey, which asks whether people trust scientists as a source of information about environmental issues. Two-thirds of the Democrats but only 42 percent of the Republicans say that they trust scientists for information.

This question about trust in scientists was asked on NCERA and some of the regional CERA surveys, ${ }^{14}$ although not on the Granite State Poll. The CERA surveys that carried this question each found patterns consistent with the national results in Figure 7. In regional data, Democrat-Republican differences regarding trust in scientists ranged from just 6 points in Appalachia to 39 points in the Pacific Northwest, but they all went in the same direction: Democrats more often trust scientists for information on environment-related topics.

\section{Discussion}

Responses from New Hampshire residents broadly resemble those on our national survey. Majorities on both express confidence that they understand either a great deal or a moderate amount about climate change. Majorities also believe that climate change is happening now, caused mainly by human activities, and majorities think that most scientists agree on this point. Deep partisan divisions appear on both surveys, but they are deeper in New Hampshire, 
FIGURE 7: WOULD YOU SAY THAT YOU TRUST, DON'T TRUST, OR ARE UNSURE ABOUT SCIENTISTS AS A SOURCE OF INFORMATION ABOUT ENVIRONMENTAL ISSUES?

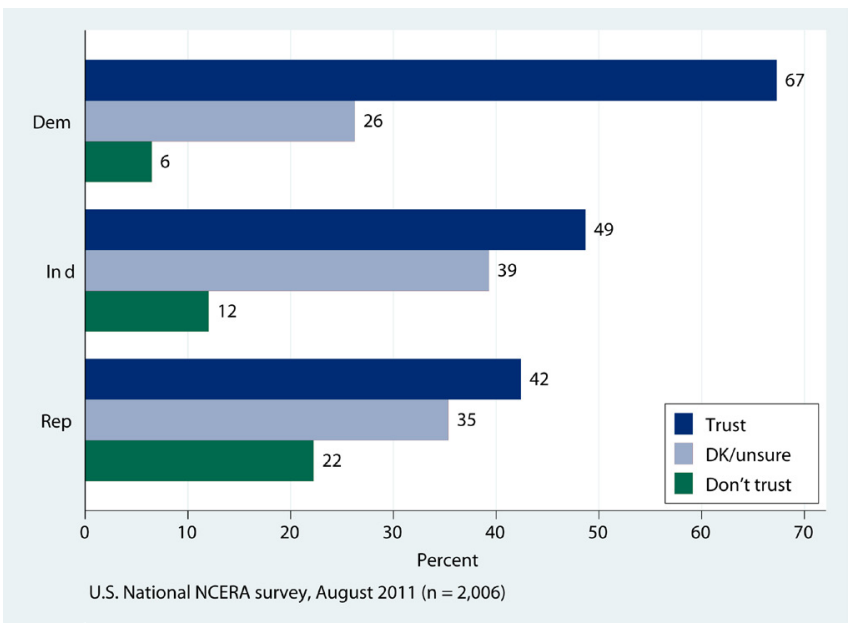

Note: All percentages are weighted.

where people also feel better informed. Both differences are consistent with the state's relatively high levels of education, and with political awareness fueled by its first-in-the-nation presidential primary.

At first glance, the partisan divisions in Figures 3 and 6 might be read as symmetrical bias: Democrats believe one thing and Republicans another. Figure 7, however, emphasizes that the bias is asymmetrical with respect to science. Democrats are more inclined to trust scientists, and to accept the conclusions of leading scientists and science organizations on climate change. A central point common to statements by major scientific organizations-such as those quoted earlier from the American Association for the Advancement of Science, the American Geophysical Union, and members of the National Academy of Sciences-is that climate change is currently happening, caused mainly by human activities. Our surveys clearly show that most Democrats believe this point, whereas most Republicans do not.

Partisan contrasts regarding climate change are especially pronounced among people who feel they understand the issue well. It seems likely that those with high "understanding" do indeed have more information, but that such information often is acquired selectively, in a manner that supports preexisting political beliefs. More detailed investigation of knowledge, and how people gain it, forms the next step in our research.

\section{Box 1: New Hampshire and National Surveys}

The Granite State Poll has been tracking opinions of New Hampshire residents since 2001. Four times each year, trained interviewers at the University of New Hampshire's Survey Center conduct telephone interviews lasting 10 to 15 minutes each with representative samples of about 500 state residents. The questions cover a variety of topics, including election and political issues. The upper plots in Figures 1-5 show results from one poll conducted in June 2011. Figure 6 places these results in the context of six other polls.

In 2007, researchers at the Carsey Institute of the University of New Hampshire began a series of regional surveys to study Community and Environment in Rural America (CERA). Most of these surveys also were conducted by interviewers at the UNH Survey Center. CERA surveys are somewhat longer than the Granite State Poll, asking a wider range of non-political questions and lasting about 20 minutes each. More than 18,000 CERA interviews have been completed since 2007, in rural regions ranging from southeast Alaska to northern Maine and the Gulf of Mexico coast.

For the next step in this research, the CERA team designed a comparable nationwide survey called NCERA. Unlike the rural CERA surveys, NCERA aimed for a nationally representative sample including both urban and rural residents, from all fifty states. The UNH Survey Center carried out NCERA interviews with 2,006 people in August 2011. The results provide national benchmarks for questions that had also been asked in particular geographical regions by CERA or the Granite State Poll. The lower plots in Figures 1-5 of this brief take a comparative look at some results from NCERA.

Both NCERA and the Granite State Poll employ random sampling and probability weighting methods to obtain results that represent U.S. or New Hampshire populations, and they check these results against census profiles. The margins of error (approximate 95\% confidence intervals) for weighted percentages from NCERA in Figures 1, 2, and 4 are less than plus or minus 3. For the Granite State Poll results in Figures 1, 2, and 4, the margins are less than plus or minus 5 . 


\section{Box 2: Three Questions about Climate Change}

Since April 2010, three questions about climate change have become regular features on the Granite State Poll, and have also been carried on the CERA regional surveys. The same three questions were included on the NCERA national survey in August 2011. These questions are neutrally worded, and designed around a central point of statements made by the major scientific organizations. To avoid possible bias the order of the second and third questions, and of their responses, is rotated in different interviews.

"Next, I would like to ask you some questions about the issue of global warming or climate change. How much do you feel you understand about this issue-would you say a great deal, a moderate amount, only a little, or nothing at all?"

A great deal

A moderate amount

Only a little

Don't know/Nothing at all

"Which of the following three statements do you personally believe?

Climate change is happening now, caused mainly by human activities.

Climate change is happening now, but caused mainly by natural forces.

Climate change is not happening now."

(don't know - volunteered)

"Which of the following two statements do you think is more accurate?

Most scientists agree that climate change is happening now, caused mainly by human activities.

There is little agreement among scientists whether climate change is happening now, caused mainly by human activities."

(don't know - volunteered)

\section{Box 3: "Global Warming" or "Climate Change"?}

One of our questions asks people how much they understand about the issues of "global warming or climate change." The others refer only to "climate change." What is the difference between these terms?

Scientists view global warming and climate change as distinct concepts, with some overlap in practice. "Climate change" refers to long-term changes from any cause. Such changes could be global or regional in scale, and include up or down shifts not just in temperature but in storms, precipitation, and so forth. "Global warming" is a more specific and recent term, generally credited to a 1975 paper by geochemist Wallace Broecker. It describes an increase in the Earth's average surface temperature caused by rising greenhouse gas concentrations. Global warming certainly is climate change, but its specific effects can differ across regions, even cooling some places despite (or because of) rising average temperatures.

Many scientists prefer to use the more inclusive term "climate change", as in the passages quoted for this brief. Other examples include the Intergovernmental Panel on Climate Change (IPCC), founded in 1988 to conduct broad interdisciplinary reviews of climate research, and the scientific journal, Climatic Change, publishing studies since 1977. "Global warming" sounds more colorful, but has given rise to some public confusion. Non-scientists sometimes miss the idea that "global warming" refers to an upward trend in the global average, over many decades. It does not imply that every place should get warmer, or each year should be warmer than the last. Our two factual questions, like the statements by scientists on which they are based, use the term "climate change." Respondents could say whether they believed climate is changing, and if so whether for human or natural reasons. 


\section{EN D N O T ES}

1. Mil Duncan, Tom Safford, Curt Grimm, David Moore, Chris Colocousis, and Jessica Ulrich at the Carsey Institute helped to conceptualize and carry out the first cycle of CERA surveys. The UNH Survey Center conducted most of the telephone interviews, including all of those after CERA's first year (2007). Further descriptions and results from CERA can be found in papers or reports, including:

L.C Hamilton et al., Place Matters: Challenges and Opportunities in Four Rural Americas (Durham, NH: Carsey Institute, University of New Hampshire, 2008). Available at http://carseyinstitute.unh.edu/publications/Report_ PlaceMatters.pdf.

L.C. Hamilton and B.D. Keim, "Regional variation in perceptions about climate change," International Journal of Climatology 29(15) (2009): 2348-2352.

L.C. Hamilton, C.R. Colocousis, and C.M. Duncan, "Place effects on environmental views," Rural Sociology 75(2) (2010): 326-347.

L.C. Hamilton, T.G. Safford, and J.D. Ulrich (in press), "In the wake of the spill: Environmental views along the Gulf Coast," Social Science Quarterly.

2. L.C. Hamilton, "Do scientists agree about climate change? Public perceptions from a New Hampshire survey," New England Issue Brief No. 22 (Durham, NH: Carsey Institute, University of New Hampshire, 2010). Available at http:// www.carseyinstitute.unh.edu/publications/IB_Hamilton_ Climate_Survey.pdf.

3. L.C. Hamilton, "Climate change: Partisanship, understanding and public opinion," Issue Brief No. 26 (Durham, NH: Carsey Institute, University of New Hampshire, 2011). Available at http://www.carseyinstitute.unh.edu/publications/IB-Hamilton-Climate-Change-2011.pdf.

4. T.G. Safford and L.C. Hamilton, "Ocean views: Coastal environmental problems as seen by Downeast Maine residents," New England Policy Brief No. 3 (Durham, NH: Carsey Institute, University of New Hampshire, 2010). Available at http://www.carseyinstitute.unh.edu/publications/ PB_Safford_DowneastMaine.pdf

Hamilton, Safford, and Ulrich (in press), "In the wake of the spill: Environmental views along the Gulf Coast."

5. L.C. Hamilton, B.D. Keim, and C.P. Wake, "Is New Hampshire's climate warming?" New England Policy Brief No. 4 (Durham, NH: Carsey Institute, University of New Hampshire, 2010). Available at http://www.carseyinstitute.unh. edu/publications/IB_Hamilton_Climate_Survey_NH.pdf.

6. American Association for the Advancement of Science, "AAAS Board releases new statement on climate change." Available at http://www.aaas.org/news/releases/2007/0218am_ statement.shtml, accessed 10/28/2011.
7. American Geophysical Union, "AGU revises position on climate change," 2008. Available at http://www.eurekalert. org/pub_releases/2008-01/agu-arp012508.php, accessed $10 / 28 / 2011$.

8 . N. Oreskes, "The scientific consensus on climate change," Science 306(5702) (2004): 1686.

9. G8+5, "G8+5 National Academies' joint statement: Climate change and the transformation of energy technologies to a low carbon future," National Academies of Brazil, Canada, China, France, Germany, India, Italy, Japan, Mexico, Russia, South Africa, UK, and USA, 2009. Available at http://www.nationalacademies.org/includes/G8+5energyclimate09.pdf.

National Research Council, Advancing the Science of Climate Change (Washington, DC: National Research Council of the National Academies, 2010).

10. Intergovernmental Panel on Climate Change, Climate Change 2007-The Physical Science Basis, Contribution of Working Group I to the Fourth Assessment Report of the Intergovernmental Panel on Climate Change (Cambridge: Cambridge University Press, 2007).

K. Richardson et al, Synthesis Report from Climate Change: Global Risks, Challenges \& Decisions (Denmark: University of Copenhagen, 2009). Available at http://www.pik-potsdam. de/news/press-releases/files/synthesis-report-web.pdf.

11. P.T. Doran and M.K. Zimmerman, "Direct examination of the scientific consensus on climate change," EOS 90(3) (2009): 22-23.

12. P.H. Gleick et al., "Climate change and the integrity of science," Science 328(5979) (2010): 689-690.

\section{For example, see:}

Hamilton, "Climate change: Partisanship, understanding and public opinion."

L.C. Hamilton, "Education, politics, and opinions about climate change: Evidence for interaction effects," Climatic Change 104 (2011): 231-242.

A.M. McCright, "Political orientation moderates Americans' beliefs and concern about climate change," Climatic Change DOI: 10.1007/s10584-010-9946-y (2011).

A.M. McCright and R.E. Dunlap, "The politicization of climate change: Political polarization in the American public's views of global warming," Sociological Quarterly 52 (2011): 155-194.

14. See Hamilton, "Climate change: Partisanship, understanding and public opinion." 


\section{A C K K N O W L E D G E M EN T S}

The author would like to thank Mil Duncan, Curt Grimm, Joel Hartter, Megan Henly, Tracy Keirns, David Moore, Tom Safford, Andrew Smith, Jessica Ulrich, and Justin Young at the Carsey Institute who helped to conceptualize and carry out these surveys. Cliff Brown, Leslie Hamilton, Laurel Lloyd Earnshaw, Bruce Mallory, Barbara Ray, and Amy Sterndale offered valuable assistance, comments, and suggestions for this brief.

\section{A B OUT THE AUTHOR}

Lawrence C. Hamilton is a professor of sociology at the University of New Hampshire and a senior fellow at the Carsey Institute (lawrence.hamilton@unh.edu).

\section{A UNIVERSITY Ii. of NEW HAMPSHIRE}

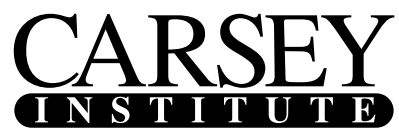

Building knowledge for families and communities

The Carsey Institute conducts policy research on vulnerable children, youth, and families and on sustainable community development. We give policy makers and practitioners timely, independent resources to effect change in their communities.

This work was supported by grants from the Ford Foundation, the Neil and Louise Tillotson Fund, the Office of Rural Development in the U.S. Department of Agriculture, and at the University of New Hampshire (UNH) by the Office of Sustainability and the Carsey Institute.

Huddleston Hall

73 Main Street

Durham, NH 03824 